\title{
Structural Design of Concrete Structure Using E-Tabs
}

\author{
Shivam Asawa ${ }^{\# 1}$, Anurag Sarda ${ }^{\# 2}$, Husain Seva ${ }^{\# 3}$, Rajas Mohite ${ }^{\# 4}$, Rajat Singh \\ Manhas $\#$ \\ ${ }^{\# 1,2,3,4,5}$ Student, Department of Civil Engineering, Sinhgad Academy of Engineering, India.
}

\begin{abstract}
In the world of technology and evolution, the field of civil engineering has also grown in various dimensions. Earlier the analysis and sustainability of the civil structures used to be paper based calculations which led to insufficient accuracy of analysis and variable factors affecting the failure of the structure through inevitable instances. But with the help of integration of various engineering fields, this determination of various characteristic changes, durability, deformation or failure caused due to hidden factors which are left out in the manual calculations i.e. paper based have converted and led this system to whole new level. Now a number of software are developed for analysis, computation and management of building of civil structures which are highly precise. This document provides the various uses, merits of the software E-Tabs in the construction field and in the analysis of the concrete structures as well as steel structures.
\end{abstract}

Keywords: Analysis, Software, Structure, Highly precise, Durability, Concrete structures, E-Tabs.

\section{Introduction}

India is a developing country and has developed in every sense since its independence. The most important are the infrastructural development which is to be provided in order to generate an efficient way to work. Infrastructure has become very important in today's era, since it has been the key factor in the growth of a country, be it in information technology, logistics or any other senses. The presence of high rise buildings in a country displays its economic strength. Now in India in cities like Mumbai, the government is sanctioning the construction of high-rise buildings. As of next year, Mumbai will be the city having the world's tallest residential building named World one. Building these megastructures has become common in today's world since it is the only way in which humans can make the maximum use of the piece of land. But the main concern is when the designing part of these high rise structure comes into play. Unlike the old times, the designing of the building was done manually. Until the innovation into civil engineering field which started the use of computeroriented design software into the process of designing of a structure or a high rise building.

Today there are hundreds of software which consult into the designing of the civil related structures and also managerial software which deals with the management of the construction activities on the site. The various software in the field of designing are namely E-Tabs, STAAD.pro, SAFE etc. These are most widely used software around the world.The main focus being on E-Tabs software.Since in India, it is been used from recent past even though it has been existing since last three decades.The software ETABS has an ultimate integrated system which helps in computing the values required for the designing and analysis of the building. It has been used in some of the most renowned building projects the mankind has known. E-tabs was used to create the mathematical modelling of the BurjKhalifa, currently the tallest building the world, designed by Chicago, Illinois-based Skidmore, Owings and Merrill (SOM). Various factors like gravity, wind and seismic response were all characterized using ETABS. ETABS is commonly used to analyse skyscrapers, parking garages, steel and concrete structures, low-rise buildings, portal frame structures, and high rise buildings.

Concrete structures provide a vast availability in the field of civil engineering. It has redefined the construction methods and building high-rise structures at easy. Concrete structures also include various structures like Dams, retaining walls, bridges and skyscrapers. After the introduction of concrete cement in before Christ era, it has been in the construction field since then. It is the basic requirement for the building of any structure which is of vital importance. In India concrete structures are used almost everywhere, even the simple residential blocks are concrete made unlike in western countries where the houses are made of wood. Concrete has been the most favourable material in the field of construction because of its properties as it is durable, strong, resistant and reliable. It is used under various types of Reinforced Cement Concrete, plain cement concrete, and various under the same categories. The necessity and importance of concrete are immense.

\section{Objective}

1. To understand basic principles of the structure using IS codes.

2. To analyse the structural details of the structure.

3. To understand the design parameter of the beams, slab, column, staircase and other structural entities.

4. To prepare the 3D model of the structure by use of the software for detailed design and analysis. 
5. To design $\mathrm{G}+3$ residential building using ETABS software in order to design and analyse the building to its maximum accuracy and economic value.

\section{Progress Of Work}

1. The seminar topic "Design of an RCC structure using ETABS", starts with drafting a plan of building in AUTO CADD software. After completion of the drafting process, the designing of the slab, beam, and column is to be done. The design of the columns, beams, slabs (Two-way and one-way slab) have been done according to IS 456 norms. The procedure as follows, starting with the data collection for the designing of the particular building. In which the information like type of the building, building plan, floor to floor height, plinth height, depth of foundation, BCS of soil, wall thickness, and assumed loading factors including floor finish, roof finish, live load and dead load. The material to be used in the structure is to be defined too.

2. Additionally, structural planning of the purposed project for deciding the position of columns, followed by positioning of beams and spanning of slabs. The numbering and nomenclature for members are then done in order to facilitate the easy in the practice of designing of the member. Sizing of beams and column is to be done according to the specific need of the building. Ultimate load which is also called as factored load for the given member. These comprise of a load of the roof, floor, and bath -WC, loft and balconies.

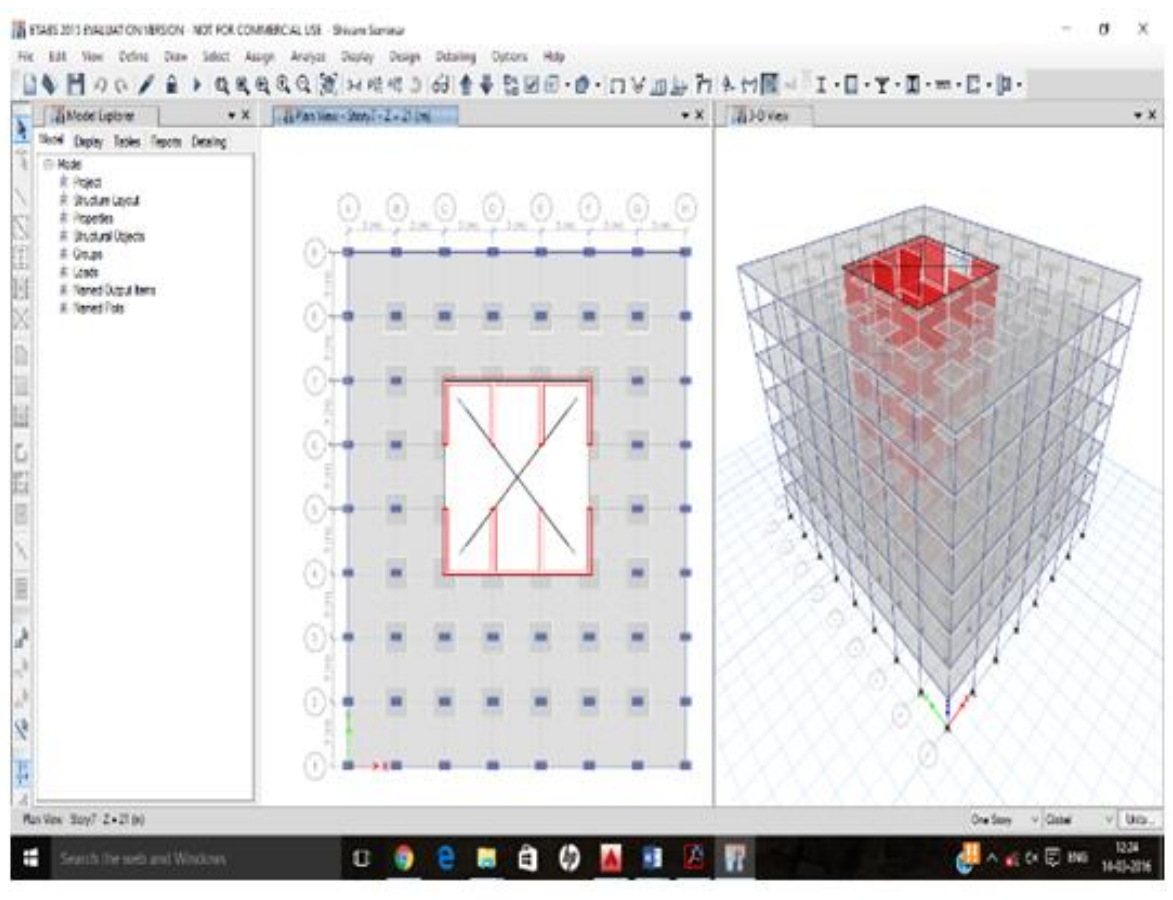

Figure 1: Screenshot of the ETABS software during designing

3. Then comes on of the very important designing procedure, design of the beam. In which the designing of roof beam, floor beams, and plinth beams are done. After the designing of the beams, designing of the column section is done, which comprises of columns in top storey, in an intermediate storey and in the first storey. This all comprises of end columns, intermediate columns and a number of columns on each floor.

4. The design of footing is then done. All the footings are to be designed according to the bearing capacity of the soil below the foundation level of the soil, for example, the bearing capacity of the soil is reasonably low then all the footings are to be designed for axial loads.

5. Finally, the designing of the slabs is carried out using the IS 456, depending upon the type of the slab i.e. one way, two way, continuous, non-continuous etc.

6. Thus, this all detailed calculations and designing steps are summarised and presented. After the manual calculations, the software ETABS is used for analysing the same design parameters.

7. In ETABS, there are simple steps which one needs to follow in order to complete analysis and design of a multi-storey concrete building. These procedures require various specifications, dimensions and other important factors such as load which is to be acted upon the building due to the natural forces etc. It has become a convenient method of analysis which has the ease to create the plan and analyse it all together in one single click of the mouse. 
8. ETABS also takes into account building standard codes which are in use all over the world (variety of building codes) and generates animation for deflection due to wind, earthquake etc. external forces acting on the building.

\section{Advantages}

Various enhancement is been included in the ETABS which has made significant changes and easier modelling and designing of the buildings. Some important mentions are as follows:

1. The inclusion of international design codes. The software consists of various international codes which are used worldwide such as ASCE 7-10, ASCE 7-05, ASCE 7-02, Italian NTC 2008, Eurocode 8 2004, IS 1893 2002, NBCC 2010, Turkish Seismic Code 2007 etc.

2. The addition of various specifications of the components of the structures such as Enhancement limiting the total effective width of $1 / 4$ the span of the beam and taking in account the amount of deflection caused by shrinkage of concrete in Slab/Beam design.

3. Automated seismic lateral loading has been implemented.

4. A new stable check for nonlinear direct integration time history analysis has been increased for models containing more than one or multiple linear shell elements. Several other enhancement have been implemented for beam designs to increase productivity and to improve reporting.

5. Better and accurate calculation of design values.

6. Faster and more economical design of the structures.

\section{Literature Review}

1. High Rise Buildings and How They Affect Countries Progression (Dr.Akram Farouk) stated that Facades must be distinct and able to achieve a good balance between form and economic cost, Creating laws and principles governing high rise buildings construction in order to stimulate capital and investment in such projects formation of various an investment committee which will provide all the required economic studies in order to ensure the success of the projects.

2. Study of High Rise Residential Buildings in Indian Cities (A Case Study -Pune City) (RupaliKavilkar and Shweta Patil) stated high-rise residential structures are not popular due to user perception that they are expensive and the associated fear of safety during a fire. The study concludes that fly ash is available abundantly, but not used to it full extent in the construction industry. The study of fly ash as a material reveals that it can be more economical to use fly ash in high-rise structure and in minimizing the potential damage due to high temperatures.

\section{Conclusion}

It concludes that the efficiency and reliability of the software in the field of designing is much better to that of the manual work. It has been seen that the software generated results were more efficient and economical which included the various different conditions under the designing conditions which are difficult to consider when done manually.

\section{References}

[1]. Dr.Akram Farouk, Assistant Professor Ain Shams University Faculty of Engineering Department of Architecture Cairo ,Egypt.High Rise Buildings and How They Affect Countries Progression.

[2]. N. Subramanian- Design of Reinforced Concrete Structures, Oxford University Press

[3]. Dr. V.L. Shah, Dr. S.R. Karve- Illustrated Design of Reinforced concrete buildings, $7^{\text {th }}$ edition.

[4]. Bureau of Indian Standards 456-2000- Indian Standard plain and reinforced concrete code of practice (4 ${ }^{\text {th }}$ edition) 